\title{
Research on the performance evaluation of government venture capital fund based on factor analysis and DEA model
}

\author{
Hong-Mei Zhang ${ }^{1,2,3}$, Ya-Zhong Chen ${ }^{1,2,3}$,Zhe Wang ${ }^{1,2,3}$ \\ ${ }^{I}$ Guizhou University of Finance and Economics, Guizhou Institution for Technology Innovation \\ \& Entrepreneurship Investment, Guiyang Guizhou 550025, China \\ ${ }^{2}$ Guizhou University of Finance and Economics, Guizhou Institute for Urban Economics and \\ Development, Guiyang Guizhou 550025, China \\ ${ }^{3}$ Guizhou University of Finance and Economics, School of Finance, Guiyang Guizhou \\ 550025, China
}

Received 8 January 2016

Accepted 27 February 2016

\begin{abstract}
According to the existing domestic and foreign research results as well as the characteristics of the guide fund, this paper constructs the index system of guide fund performance evaluation, selects the data of the part of the enterprises shared by the government guide venture capital fund and uses the factor analysis method to optimize the evaluation model, then uses empirical analysis based on DEA-BCC model. The result shows that the optimized evaluation model can fully evaluate the performance of the guide fund. At the same time, empirical analysis based on DEA-BCC model shows that the results can objectively reflect the operating conditions of companies accepted investment, which provides the objective reference for government venture capital fund and companies accepted investment.
\end{abstract}

Key words: Government venture capital fund, performance evaluation index system, factor analysis method, DEA method

\section{Introduction}

At present, with the continuous improvement of financial system and technology in China's financial industry, the transaction cost and opportunity cost of financial products in the field of financial market are gradually reducing, and the financial industry in China is entering a rapid development and constantly growing. Among the many financial products in the financial market, all kinds of fund products with their high efficiency fast pace of the characteristics, as one of the important pillars of the financial market, have been the rapid development of universal. Among them, the government venture capital fund as one of the policy funds, has played a positive role in the early stage of small and medium enterprises, and the government's macroeconomic regulation and control to focus on the key development areas plays a role in the regulation of financial markets and stimulate market activity. In "Guidance on the Establishment and Operation of the Guide Fund for Venture Capital"[1], though the proposed "will guide the fund into the public finance evaluation system", the integrity is insufficient, in terms of Chinese current situation and financial market system, in that the development of our country public finance expenditure performance evaluation system is late. So in the evaluation of guiding fund performance, building a reasonable and effective performance evaluation system of venture investment guide fund can help the government guide fund of venture capital in our country to develop faster.

At present, the research on the performance evaluation of the guidance fund in foreign countries has made obvious achievements. Since many foreign guide funds have been quite successful, the foreign scholars are more likely to carry out performance evaluation in the relevant research. Lerner $(1999)^{[2]}$ took the small business investment corporation of the United States as an example, and studied its ability to absorb social capital performance evaluation, in order to test the effectiveness of the actual application of SBIC program. "Compared to similar corporations, supported companies have been more rapid growth in the past ten years, and more likely to attract venture capital". Lerner's view was that the SBIC program provides an effective help for the venture capital fund to absorb the introduction of venture capital fund in the government's support. However, once government as a venture capital investment body, its ability is often not enough to assume the role of selection, evaluation of investment opportunities. David B.Audretsch et al. $(2002)^{[3]}$ used qualitative research methods and comprehensive innovation, commercialization and entrepreneurial behavior and other aspects to study the 
performance evaluation of SBIC. The results show that SBIC has a promoting effect on social production technology innovation and scientific and technological achievements. Jonathan G.S.Koppel $(2008)^{[4]}$ also assessed the SBIC, which was evaluated from the point of view of government management. It is believed that the relationship between the supervision and management of venture capital fund should not be presented as subordinate management relationship, which was due to the United States International Development Council (AID) poor supervision. So we put forward suggestions: we should pay attention to the design of government guidance fund management framework. Most of the studies in foreign countries are based on the analysis of the data samples of a specific fund to draw the overall performance. The selected variables can not be integrated into the system, and in the construction of evaluation index system, the guiding fund is not located in the public financial evaluation index system. What's more, most of the studies have neglected the importance of theoretical research.

During the ten years since the birth of China's guide fund, most scholars have gradually started to study the performance evaluation of the fund, and mostly focused on the construction of evaluation index system. Guiying Liu (2008) ${ }^{[5]}$ comprehensively used factor analysis method to classify and select indicators to construct evaluation index system, and used the DEA model to evaluate the performance of China's open funds. She improved the evaluation index system with innovative research methods, and put forward the factor analysis method, which can make the DEA model analysis results more clearly and effectively. Hongjiang Li and Xiaoyan Bao (2011) ${ }^{[6]}$ proposed that, in the analysis of the venture investment guide fund performance evaluation index system, index system should include five indicators, which reflect policy leverage, industry oriented and risk control, the government support and fund increment, thus to comprehensively and systematically reflect the focus of government policy. Bo Gui $(2009)^{[7]}$ used factor analysis and DEA model to evaluate the competitiveness of the 16 listed banks, and the results showed that the indexes of the competitiveness of listed banks in China were the innovation, scale and profitability of the bank. Yu Yu (2013) ${ }^{[8]}$ viewed the policy objectives, policy effects and operational capacity as the main factors to analyze the impact of the government venture capital to guide the performance of the fund, and proposed improving suggestions for the problems in the process of assessment, so as to pave the way for building evaluation index system. Zhipeng Qin $(2014)^{[9]}$ constructed the performance evaluation index system, which accords with the current situation in China, with the aid of economic history analysis method, mathematical economics method and econometric model method is based on the characteristics of China's venture capital fund. According to the conclusions, there are problems such as the contradiction between the regional distribution of the fund and the adjustment of regional economy in China. Research on performance evaluation of venture capital fund in China is still in the exploratory stage. At present, it has not been able to meet the regulatory requirements of the index system and theoretical methods in the "Guidance". With the theoretical research gradually deepening, the evaluation index system established by the domestic scholars tends to combine policy leverage and industry oriented and other indicators to put forward the innovative evaluation method and index system. This paper, based on the previous research achievements, will try to use factor analysis and DEA method to study the performance evaluation of venture investment guide fund. The results show that using this method can be more effectively evaluate the performance of the guide fund, and provide objective evaluation conclusion for the venture investment guide fund and the investment enterprise development, which has a certain reference value.

\section{Evaluation Index and Sample Data}

For the analysis of the venture investment guide fund performance, this paper synthesizes the domestic and foreign existing research results and the guide fund characteristics, and analyzes guide fund policy goals, economic benefits and risks of three factors specifically. In accordance with the scientific, reliable and objective principles and considering the efficiency of fund and risk etc. factors, the selected indicators are as follows: the fund investment scale, leverage effect, business profits, income growth rate, investment risk and profit growth rate.

On the policy objectives of the investment guide fund, the purpose of the government to guide the establishment of the fund is to attract social capital by way of increasing treasury investment to support industries. On the one hand, it save treasury expenses, on one hand, play a role in amplifying the leverage effect. Investment scale is the asset values of the Investment guide fund, which reflects the situation of enterprises receiving guidance fund investment at the beginning of the period. Leverage Effect Index shows the multiples of the guide fund drive social capital, which can measure the policy effect and risk. These two indicators are inputs of the venture investment guide fund, which reflects the government's policy guidance. Also, the guide fund acts as a financial product, which plays the function of financial funds to control the market through investment funds to enterprises to produce economic benefit, and the fund needs to keep its value for the long-term operation. Hedging means is that the investment benefits through the maintenance of capital circulation, so the economic 
benefit of the fund is one of the factors to assess the performance of the fund. The operating profit and total profit indicators reflect the profit level of the enterprises receiving the guide fund investment at the end of the term, and the profit growth rate is the total profit of the enterprises at the end of the period, reflecting the business situation. Venture investment guide fund as a kind of venture capital, of which the operation risk is an important evaluation index. This paper selects $\beta$ value as risk metrics, and at the same time, enterprise profit growth rate reflects the business situation to accept the investment and the management ability, which is the risk assessment of the selection of the guide fund investment.
This paper selects 10 companies to analyze the data in 2013. The investment scale and the leverage effect data are from the Ministry of Science and Technology of the People's Republic of China, the company's operating profit, total profit and profit growth rate data from its financial statements, investment risk data are from the enterprise beta. On the basis of the above six indicators, factor analysis method is used to screen, identify the representative factors and use the DEA model for empirical analysis to conduct empirical research on the performance of the guide fund.

The indicator system and data are shown in Table 1, using the serial number for each enterprise data number from 1-10:

Table 1. Government venture capital fund performance evaluation index and data

\begin{tabular}{|c|c|c|c|c|c|c|c|}
\hline $\begin{array}{l}\text { Fund } \\
\text { order }\end{array}$ & Guiding fund shares enterprise & $\begin{array}{l}\text { Investment } \\
\text { scale }\end{array}$ & Leverage & Operate profit & $\begin{array}{l}\text { Investment } \\
\text { risk }\end{array}$ & Total profit & $\begin{array}{l}\text { Profit growth } \\
\text { rate }\end{array}$ \\
\hline 1 & $\begin{array}{l}\text { Datang Telecom Polytron } \\
\text { Technologies Co., Ltd }\end{array}$ & 56200270.2 & 5 & 155615858.74 & 1.03 & 265251721.2 & $25 \%$ \\
\hline 2 & $\begin{array}{l}\text { Shanghai Kangda Chemical } \\
\text { New Materials Co., Ltd }\end{array}$ & 6466791.5 & 5 & 42781992.71 & 1.02 & 46653568.82 & $22.73 \%$ \\
\hline 3 & $\begin{array}{l}\text { Hubei Dinglong Chemical } \\
\text { Co., Ltd }\end{array}$ & 48899604.2 & 4 & 88726258.07 & 0.72 & 102519455.2 & $27.31 \%$ \\
\hline 4 & $\begin{array}{c}\text { Luoyang Long Hua Heat } \\
\text { Transfer Polytron Tec. Co., } \\
\text { Ltd }\end{array}$ & 30109634.1 & 4 & 67872107.25 & 0.99 & 94334990 & $15.01 \%$ \\
\hline 5 & $\begin{array}{c}\text { Jiangsu Wehrle Environmental } \\
\text { Protection Polytron } \\
\text { Technologies Co., Ltd } \\
\end{array}$ & 18045531.2 & 4 & 23646471.65 & 1.2 & 31754245.25 & $-60.15 \%$ \\
\hline 6 & $\begin{array}{l}\text { Qingdao Eastsoft Polytron } \\
\text { Technologies Co., Ltd }\end{array}$ & 15572302.4 & 4.23 & 209490271.66 & 1.25 & 273553112.9 & $-12.93 \%$ \\
\hline 7 & Changzhou Almaden Co., Ltd & 305099598.5 & 18.5 & 70125014.23 & 0.90 & 71050901.91 & $-18.35 \%$ \\
\hline 8 & $\begin{array}{c}\text { Jiangsu Xiupiang Glasswork } \\
\text { Co., Ltd }\end{array}$ & 31298193.5 & 18.5 & 36830152.96 & 1.14 & 36717814.34 & $-38.56 \%$ \\
\hline 9 & $\begin{array}{c}\text { Yangzhou Yang Jie Electronic } \\
\text { Polytron Technologies Co., } \\
\text { Ltd }\end{array}$ & 19303706.9 & 18.5 & 104710351.57 & 0.29 & 120723441.7 & $38.13 \%$ \\
\hline 10 & $\begin{array}{c}\text { Jiangsu Yawei Machine Tool } \\
\text { Co., Ltd }\end{array}$ & 37612196.6 & 18.5 & 81786430.68 & 1.28 & 94209085.07 & $3.41 \%$ \\
\hline
\end{tabular}

\section{Construction of Index System Based on Factor Analysis}

Factor analysis is the use of statistical methods. Under the premise of maintaining the stability of the index system, representative factors are selected among numerous factors, and according to the index data, the existing index is represented as a linear combination of the representative indexes, so as to reduce the dimension of the existing index system. According to the analysis results, if the cumulative variance contribution rate of the common factor is greater than $85 \%$, it is indicated that the common factor can effectively guarantee the index system without losing information after reducing the dimension ${ }^{[10]}$. The treatment process is:
First, the initial factor model is established, or:

$$
X_{i}=a_{i 1} F_{1}+a_{i 2} F_{2}+\ldots+a_{i n} F_{n}+\varepsilon_{i}(n \leq m)
$$

Among them, there are total $\mathrm{m}$ indicators, $F_{j}$ as the common factor, $a_{j n}$ as the factor component which

represents the correlation between $X_{j}$ and the various factors, $\varepsilon_{j}$ as the error. In order to explain the meaning of the common factor, the factor load is needed to rotate:

$$
X_{i}=b_{i 1} F_{1}+b_{i 2} F_{2}+\ldots+b_{i n} F_{n}+\varepsilon_{i}(n \leq m)
$$

Among them, $b_{j n}$ represents the factor component after the rotation.

Finally, each common factor is calculated to determine its score, and the factor scores are calculated, respectively: 
Factor score:

$$
F_{i}=\beta_{i 1} X_{1}+\beta_{i 2} X_{2}+\ldots+\beta_{i m} X_{m}
$$

Comprehensive score:

$$
C_{i}=\lambda_{i 1} F_{1}+\lambda_{i 2} F_{2}+\ldots+\lambda_{i m} F_{m}
$$

$C_{i}$ as the comprehensive score, $\lambda_{i}$ as the factor score. Before the factor analysis, the evaluation index system and data need KMO and Bartlett ball type test, in order to test whether it is suitable for factor analysis. After SPSS analysis, the results as shown in table 2:

\begin{tabular}{|c|c|c|}
\hline \multicolumn{2}{|c|}{ Kaiser-Meyer-Olkin metric } & 0.502 \\
\hline \multirow{3}{*}{ Bartlett ball type test } & Approximate chi-square & 25.226 \\
\hline & Df & 15 \\
\hline & Sig. & 0.047 \\
\hline
\end{tabular}

Table 2. KMO and Bartlett test

Visibly, KMO value is $0.502>0.5$, and the $\mathrm{p}$ value of the spherical test, that is, Sig value is $0.047<0.05$, says that the ball hypothesis is rejected, that is, the value of each index in the index system is correlated, which is consistent with the factor analysis of the data requirements. Therefore, the evaluation index system constructed in this paper is suitable for factor analysis.

Next, process the factor analysis of the 6 indicators data through SPSS 19.0, analysis results as shown in table 3:

Table 3. Variance Analysis of common factor

\begin{tabular}{cccc}
\hline Factor & Eigenvalue & Variance ratio (\%) & $\begin{array}{c}\text { Cumulative contribution rate } \\
(\%)\end{array}$ \\
\hline 1 & 2.353 & 39.217 & 39.217 \\
\hline 2 & 1.615 & 26.925 & 66.142 \\
\hline 3 & 1.178 & 19.631 & 85.775 \\
\hline
\end{tabular}

According to the results of factor analysis, the common factor 1, 2, 3 can better reflect the index information, the eigenvalue is above 1 , and the cumulative contribution rate of the three common factors is more than $85 \%$, that is, the common factors meet the requirements. And then according to the analysis of the gravel map, figure 1 can be shown:

Visibly, since the component 4 begins to show the slope change, the linear slope stabilizes after the component 4 . In the gravel map, the straight line slope turns at the point of the component 4 , so this paper determines the number of common factor is 3 .

Then, the property of each common factor is determined by the analysis of the rotational component matrix, as shown in table 4:



Fig. 1 factor analysis of the gravel map

Table 4. Rotational components table

\begin{tabular}{cccc}
\hline \multirow{2}{*}{ Index } & \multicolumn{3}{c}{ Common factor } \\
\cline { 2 - 4 } & Common factor 1 & Common factor 2 & Common factor 3 \\
\hline Investment scale & 0.042 & -0.088 & 0.875 \\
\hline Leverage & -0.247 & 0.143 & 0.779 \\
\hline Operate profit & 0.978 & 0.096 & -0.056 \\
\hline Investment risk & 0.095 & -0.910 & -0.191 \\
\hline Total profit & 0.979 & 0.057 & -0.139 \\
\hline Profit growth rate & 0.293 & 0.863 & -0.169 \\
\hline
\end{tabular}

From the rotation table, common factor 1 has a higher degree of interpretation of the operating profit and total profit indicators, so its definition can be defined as the output factor. Common factor 2 has a higher degree of interpretation of the investment risk and profit growth rate indicators, and the profit growth rate is the profit growth of the enterprise during the period of investment, reflecting the profitability of the enterprise and the management ability of the enterprise managers, and its value will directly affect the performance of venture capital fund; Common factor 3 has a higher degree of interpretation of the investment scale and leverage indicators, so its definition can be defined as the input factor.

Then calculate the common factor score coefficient, the results can be obtained as shown in table 5: 
Table 5. Common factor score coefficient

\begin{tabular}{cccc}
\hline Fund order & Output factor & Risk factor & Input factor \\
\hline 1 & 1.50553 & 0.14568 & -0.27165 \\
\hline 2 & -0.80061 & 0.36707 & -0.94259 \\
\hline 3 & -0.10727 & 0.91508 & -0.52582 \\
\hline 4 & -0.28986 & 0.21979 & -0.73344 \\
\hline 5 & -1.0808 & -1.36655 & -0.70833 \\
\hline 6 & 1.97371 & -0.90715 & -0.43957 \\
\hline 7 & -0.02193 & -0.31143 & 2.46606 \\
\hline 8 & -0.95242 & -0.76322 & 0.39084 \\
\hline 9 & -0.10972 & 2.10381 & 0.41313 \\
\hline 10 & -0.11664 & -0.40307 & 0.35137 \\
\hline
\end{tabular}

\section{Empirical Analysis Based on DEA Method}

According to the above analysis, the paper finally identifies three factors, which are input factor, output factor and risk factor. When using the DEA model to analyze the data validity requirements, we need to change the negative value of the common factor score coefficient table. This paper draws lessons from "Performance Evaluation of Open End Funds in China Based on Factor Analysis and DEA Method" [5], the conversion formula as shown below:

$$
C_{i j}=0.1+0.9\left(C_{i j}-\min _{i}\right) /\left(\max _{i j}-\min _{j}\right)
$$

Among them, $\max _{i j}$ represents the maximum value of the $\mathrm{j}$ item data, and $\min _{j}$ represents the minimum value of the $\mathrm{j}$ item data. After conversion, data can be positive and will not affect the results of the analysis of the DEA model. As shown in table 6:

Table 6. Common factor score coefficient after conversion

\begin{tabular}{cccc}
\hline Fund order & Input factor & Output factor & Risk factor \\
\hline 1 & 0.277151072 & 0.862052506 & 0.49218035 \\
\hline 2 & 0.1 & 0.18255694 & 0.549595431 \\
\hline 3 & 0.210041512 & 0.38684699 & 0.691715845 \\
\hline 4 & 0.155222742 & 0.333047526 & 0.51139997 \\
\hline 5 & 0.16185264 & 0.1 & 0.1 \\
\hline 6 & 0.232814457 & 1 & 0.219140377 \\
\hline 7 & 1 & 0.411992103 & 0.373633859 \\
\hline 8 & 0.452071055 & 0.137826689 & 0.256467052 \\
\hline 9 & 0.457956376 & 0.386125107 & 1 \\
\hline 10 & 0.441649627 & 0.384086155 & 0.349868025 \\
\hline
\end{tabular}

According to the data in Table 5, this paper uses DEAP Version 2.1 software to calculate the DEA-BCC performance evaluation results of the 10 funds, with input factors as input indicators, output factors and risk factors as output indicators, results as shown in table 7 .

Table 7. Securities investment fund performance DEA evaluation value

\begin{tabular}{ccccc}
\hline & Synthetical efficiency & $\begin{array}{c}\text { Pure technical } \\
\text { efficiency }\end{array}$ & Scale efficiency & Return of scale \\
\hline 1 & 0.840 & 1.000 & 0.840 & drs \\
\hline 2 & 1.000 & 1.000 & 1.000 & drs \\
\hline 3 & 0.755 & 1.000 & 0.755 & drs \\
\hline 4 & 0.818 & 0.849 & 0.964 & irs \\
\hline 5 & 0.198 & 0.618 & 0.321 & irs \\
\hline 6 & 1.000 & 1.000 & 1.000 & irs \\
\hline 9 & 0.128 & 0.137 & 0.932 & drs \\
\hline 10 & 0.127 & 0.221 & 0.576 & irs \\
\hline
\end{tabular}




\section{(1). Return of scale}

According to the results of DEA analysis, there are 4 funds in the 10 securities investment funds which are in the state of diminishing returns to scale, that is, the problem of output redundancy, indicating that the enterprises should appropriately reduce the input size so as to keep the input and output in a more efficient state. There are 4 funds in the state of increasing returns to scale. That is, owing to less investment by the enterprises, the production scale is not up to the best state, so it should appropriately increase the amount of input. The return of scale of other two funds is unchanged, which shows that the enterprise has been in the production and operation of the maximum efficiency of input and output efficiency.

\section{(2). Synthetical efficiency}

Observing the efficiency of the 4 funds with diminishing returns to scale, as can be known, its Synthetical efficiency is lower than 1 , and the reason that the efficiency of the fund 1,3,9 is low is the lower scale efficiency, whose pure technical efficiency is 1 , that is, the enterprises need to increase capital investment; fund 4 with diminishing returns to scale is caused by two factors. In addition, the Synthetical efficiency of the 4 funds of increasing returns to scale is low, and the reason is that both pure technical efficiency and scale efficiency are low. That is, the enterprises need to adjust their production scale as well as improve the management level of the company. In conclusion, the 8 fund invested enterprises still have space to improve, and need to adjust their own production to improve the comprehensive efficiency.

\section{(3). Pure technical efficiency}

In these 10 funds, the pure technical efficiency of 5 funds is less than 1 , respectively, $4,5,7,8,10$, which shows the corresponding invested companies should improve the management level of technology to promote their pure technical efficiency and improve the Synthetical efficiency. The pure technical efficiency of the fund $1,2,3,6,9$ is 1 , indicating that for the corporations of the investment of these funds, the use of resources is efficient in the current level of investment in the technology.

\section{(4). Scale efficiency}

The scale efficiency of 8 funds is less than 1 , respectively, $1,3,4,6,7,8,9,10$, indicating that the enterprises of the investment of the 8 funds are not currently effective, but also there is a certain improvement in space.

\section{Concluding remarks}

Based on the reference to relevant literatures of the domestic and foreign scholars about the performance evaluation of the government venture capital fund, this paper chooses 6 indexes used to fully reflect the performance of guide funds and constructs the index system of guide fund performance evaluation, combined with actual situation of our country and the characteristics of guide funds. After collecting the data of 10 enterprises shared by the government guide venture capital fund, we uses the factor analysis method to optimize the evaluation model to the one including input index and output index and risk index, a total of three common factors, and then uses empirical analysis based on DEA-BCC model. The result shows that most of the current guide funds are insufficient in the aspect of the production efficiency. At the same time, empirical analysis based on DEABCC model shows that the results can objectively reflect the operating conditions of companies accepted investment, which provides the objective reference for government venture capital fund and companies accepted investment.

\section{References}

[1] Ministry of Commerce, Ministry of Finance, National Development and Reform Commission, Guidance on the Establishment and Operation of the Guide Fund for Venture Capital, 2008.

[2] Lerner, Joshua. The Government as Venture Capitalist: The long-run impact of the SBIR Program[J].Journal of Business, 1999,(72):285-318.

[3] David B.Audretsch, Albert N.Link, John T.Scott. Public/private Technology Partnership: Evaluating SBIR-Support Research[J]. Research Policy, 2002,31(1):145-158.

[4] Jonathan G.S.Koppel, The Challenge of Administration by Regulation :preliminary Findi ngs Regarding the U.S. Goverment's Venture Capital Funds. Journal of Public Administration Research an Theory, 2008.

[5] Guiying Liu, Performance Evaluation of Open End Funds in China Based on Factor Analysis and DEA Method[D], Central South University, Changsha, 2008.

[6] Hongjiang Li, Xiaoyan Bao, Research on the Performance Evaluation of Government Oriented Venture Capital Fund $[\mathrm{J}]$, Business Studies, 2011,(6):112-116.

[7] Bo Gui, Research on the Competitiveness of Listed Banks Based on DEA and Factor Analysis[D], Shandong University, Jinan, 2009.

[8] $\mathrm{Yu} \mathrm{Yu,} \mathrm{Research} \mathrm{on} \mathrm{the} \mathrm{Performance} \mathrm{Evaluation} \mathrm{of}$ Government Guided Fund[D], Tianjin University, Tianjin, 2013.

[9] Zhipeng Qin, Research on the Performance Index System of Venture Capital Guiding Fund of China's Strategic Emerging Industry[D], University Of International Business and Economics, Beijing, 2014.

[10] Huili Hao, Patrick Long, Scott Curtis, Attitudes of Property Owners to Climate Change Considerations and Their Effects on Future Property Values in Coastal Communities[J], JRACR(Journal of risk Analysis and Crisis Response), 2012,(12):185-191. 